\title{
Surgical outcome of intradural extramedullary meningiomas without dural resection - A study on 75 cases
}

\author{
Kaushik Roy', Partha Ghosh'2, Suniti Kumar Saha ${ }^{3}$, Parimal Tripathy ${ }^{4}$ \\ ${ }^{1}$ Associate Professor, Department of Neurosurgery, Nil Ratan Sircar Medical College, Kolkata, West Bengal, India, ${ }^{2}$ Ex-Senior \\ Resident, Department of Neurosurgery, Nil Ratan Sircar Medical College, Kolkata, West Bengal, India, ${ }^{3}$ Professor and \\ HOD, Department of Neurosurgery, Nil Ratan Sircar Medical College, Kolkata, West Bengal, India, ${ }^{4} E x-H O D$, Department of \\ Neurosurgery, Nil Ratan Sircar Medical College, Kolkata, West Bengal, India
}

Background: Spinal tumor is a common cause of morbidity in otherwise healthy population, timely diagnosis and treatment of spinal tumor gives excellent outcome. Aims and Objective: We report experience and clinical outcomes of 75 cases with Intradural extramedullary meningiomas operated in last 21 years. Materials and Methods: All the patients were clinically assessed with Nurick's Grading (both pre and post operatively). MRI was the main armamentarium for operating planning. In all the patients dural attachments were coagulated without any dural excision. Results: Out of 75 patients, $65 \%$ were female. Peak incidence was noted in $4^{\text {th }} \& 5^{\text {th }}$ decade and majority of patients having tumor in the thoracic spine and lateral to the cord. The entire patient showed remarkable clinical improvement according to Nurick's grade. Total removal was achieved in 69 (90.2\%) patients. Two patients had re-growth of tumor in $1 \mathrm{yr}$. follow up. No postoperative mortality noted in the present series.Conclusion: Spinal meningioma excision without dural resection did not show any increase in recurrences.

Key words: Meningioma; Intradural extramedullary; Nurick's grade

\section{INTRODUCTION}

Meningiomas represent the $2^{\text {nd }}$ most common tumors following Schwannoma and accounts for about $25-46 \%$ of all spinal canal tumors. ${ }^{1}$ Spinal Meningiomas presumably arise from meningothelial arachnoid cluster cells and therefore are located at the exit zone of the nerve roots or, the entry zones of arteries into the spinal canal. Those origins account for the tendency of the tumors toward lateral or anterolateral location. ${ }^{2}$ Though, uncommonly they are also found in the posterior to the spinal cord and they may occur at any level along the spinal axis but about $80 \%$ are thoracic. ${ }^{3,4}$ Meningiomas arise in any age group, but the majority of them occur in individuals between the fifth and seventh decades of life. Early diagnosis and surgery produce excellent results in general. The purpose of this study is to share our experience regarding clinical outcomes of 75 cases with Intradural Extramedullary (IDEM) meningiomas, which were operated in last 21 years.

\section{MATERIALS AND METHODS}

This study includes 75 cases of IDEM meningiomas operated consecutively at Bangur Institute of Neurology \& N.R.S. Medical College, Kolkata in last 21years(1996 2017). These tumors with respect to their location, clinical features at the time of admission and discharge (assessed according Nurick's Grading) ${ }^{5}$ and operative outcome has been analyzed with a mean duration of follow-up of 1year after surgery. No cases other than IDEM location were included in this study. 19 patients were not available at 1year after operation for assessment as they lost from follow up. As almost all patients presented with some difficulty on walking at the time of diagnosis, Nurick's grading was

Address for Correspondence:

Dr. Partha Ghosh, Department of Neurosurgery, Nil Ratan Sircar Medical College, Kolkata, West Bengal, India. Phone: +919007750929.

E-mail: ghoshparthanrs@gmail.com (C) Copyright AJMS 
selected for their clinical assessment in this study.All the patients were evaluated with MRI (Plain \& contrast study) before taking operative interventions.

\section{RESULTS}

Fifty four females and 21 males' patients were included in this study. Peak incidence of the disease was found to be in $3^{\text {rd }}$ and $4^{\text {th }}$ decade and majority of them presented with weakness of both lower limbs $(78 \%)$ followed by sensory changes $(63.4 \%)$. Majority of the tumors were found in the thoracic spine and laterally placed. The patient demographics regarding age, gender, symptomatology, clinical findings, Nurick's grading, surgical outcome etc. are depicted in Tables 1-9.

Among total 75 patients, 13 females and 6 males were lost at 1 year follow up.

\section{Surgical strategy}

- Posterior/Posterolateral Tumors

- Laminectomy

- Total removal

- Scrapping or removal of inner dural layer

- Coagulation of dural attachments

- Anterior/Anterolateral Tumors

- Exrended laminectomy

- Total removal if possible

- Near total removal followed by coagulation of residual tumor matrix.

\begin{tabular}{lc}
\hline Table 1: Age distribution $(\mathbf{N}=\mathbf{7 5})$ \\
\hline Age distribution & Number of patients \\
\hline $11-20 \mathrm{yrs}$ & $07(9.33 \%)$ \\
$21-30 \mathrm{yrs}$ & $10(13.33 \%)$ \\
$31-40 \mathrm{yrs}$ & $22(29.33 \%)$ \\
$41-50 \mathrm{yrs}$ & $21(28 \%)$ \\
$51-60 \mathrm{yrs}$ & $09(12 \%)$ \\
$61-70 \mathrm{yrs}$ & $06 / 05$ \\
\hline
\end{tabular}

\begin{tabular}{lc} 
Table 2: Sex distribution $(\mathrm{N}=75)$ & \\
Male & Female \\
\hline $24(32 \%)$ & $51(68 \%)$ \\
\hline $\mathrm{M}: \mathrm{F}=1.4: 3$ &
\end{tabular}

\section{Table 3: Duration of symptoms $(\mathrm{N}=75)$}

\begin{tabular}{lc}
\hline Duration of symptom & Number of patients \\
\hline $0-1$ month & $04(4.8 \%)$ \\
$1-3$ months & $09(12.1 \%)$ \\
$3-6$ months & $11(14.6 \%)$ \\
6 months -1 yr & $40(53.6 \%)$ \\
1 yr - 2 yrs & $07(9.7 \%)$ \\
More than 2 yrs. & $04(4.8 \%)$ \\
\hline
\end{tabular}

\section{DISCUSSION}

Spinal meningiomas may arise in any age group but have a peak incidence between the age of 40 and 70 years. Symptoms develop below 30 years of ages only $10 \%$ of cases, and tumor infrequently occurs under the age of $15^{6}$. In our series the peak incidence was found between $31-50$ years.

The Cleveland clinic study showed $83 \%$ of meningiomas were in thoracic region and in fair sexes, whereas men had nearly equal frequency of cervical (41\%) and thoracic $(47 \%)$ lesions. The reason for this predilection for the thoracic spine in women is unknown. ${ }^{4}$ Several lines of evidence suggest that, the growth rate of meningiomas may be affected by female sex hormones. ${ }^{1,7,8}$ There is a two fold increase in the incidence in women as compared to men. ${ }^{2}$ In many series, approximately $80 \%$ of cases occur in women. ${ }^{4,6}$ The recent series, the female to male ratios in patients with spinal meningioma ranged from 3 and 4.2 to 1 , and the ages of the people affected ranged mostly from 40 to 70 years. ${ }^{1,8,9,10}$ The size or symptomatology of meningiomas frequently increases transiently in during pregnancy. ${ }^{11,12}$ Furthermore, there is a two to four fold increase in the rate of meningiomas seen in women with breast cancer as compared with age-matched control subjects. ${ }^{13}$ We didn't have such experience regarding the hormonal influence over the tumor but, the females were affected more than men also observed in the present series and female- to-male ratio is 3:1.4 (Table 2).

Most of the patients presented between 6months and 1 year (Table 3) and paraparesis was the most common symptom (78\%), followed by sensory symptoms $(63.4 \%)$. Paraparesis was noted as predominant symptom by Sang Hoon Yoon in his series in $2007 .{ }^{14}$ Though, pain is the most

\begin{tabular}{lc} 
Table 4: Clinical features $(\mathbf{N}=75)$ & \\
\hline Localized pain & $38(51.2 \%)$ \\
Radiculopathy & $18(19.5 \%)$ \\
Parasthesia & $26(34.1 \%)$ \\
Sensory changes & $48(63.4 \%)$ \\
Paraparesis & $59(78 \%)$ \\
Paraplegia & $04(4.8 \%)$ \\
Quadriparesis & $10(13.3 \%)$ \\
Bladder involvement & $18(24.3 \%)$ \\
Respiratory distress & $02(2.4 \%)$ \\
\hline
\end{tabular}

\begin{tabular}{llc}
\multicolumn{3}{l}{ Table 5: Nuriick's grade [Pre-op] ( N=75) } \\
\hline Grade 1 & Normal walk & $05(6.66 \%)$ \\
Grade 2 & Slight difficulty on walking & $16(21.33 \%)$ \\
Grade 3 & Limitation of normal work & $34(45.33 \%)$ \\
Grade 4 & Cannot walk without help & $15(20 \%)$ \\
Grade 5 & Bed ridden/Wheel chair & $05(6.66 \%)$ \\
\hline
\end{tabular}


Table 6: Distribution of tumors according to MRI $(\mathrm{N}=75)$

\begin{tabular}{lcccccc}
\hline Site & \multicolumn{5}{c}{ Position in relation to the cord } \\
\cline { 2 - 7 } & Anterior & Anterolateral & Lateral & Posterolateral & Posterior & Number \\
\hline Cervical & 01 & 03 & 03 & 04 & 00 & 11 \\
Cervicodorsal & 00 & 01 & 04 & 02 & 02 & 09 \\
Dorsal & 02 & 12 & 11 & 19 & 03 & 01 \\
Dorsolumbar & 00 & 00 & 00 & 28 & 10 & 04 \\
Number & 03 & 16 & 18 & & & 75 \\
\hline
\end{tabular}

\section{Table 7: Surgery $(\mathrm{N}=75)$}

\section{Total removal}

Near total removal

Dural resection

Coagulation of dural attachment

$69(90.24 \%)$

$06(9.76 \%)$

$00(0 \%)$

$75(100 \%)$

\begin{tabular}{lcc} 
Table 8: Complications $(\mathbf{N}=\mathbf{7 5})$ & \\
\hline Morbidity & 10 & $13.33 \%$ \\
Wound infection & 06 & $08 \%$ \\
UTI & 09 & $12 \%$ \\
RTI & 06 & $08 \%$ \\
CSF leakage & 04 & $5.33 \%$ \\
Mortality & NIL & $0 \%$ \\
\hline
\end{tabular}

common symptom in other series, ${ }^{1,4,8,9}$ pain was present in $51.2 \%$ cases in the present series.

Most meningiomas attach to the insertion of the dentate ligament and they may extend ventrally or dorsally. ${ }^{6}$ In present series, 62 patients out of 75 , attachments of the tumors were lateral to the cord and the thoracic region was affected mostly (Table 6) corroborating with other studies. $^{3,4,15}$

Ninety percentof spinal meningiomas are purely intradural in location, the remaining 10\% may have both intradural and extradural components, or may be completely extradural. ${ }^{4,6}$ Extraduralmeningiomas are considered more biologically aggressive than those in the intradural location and more common in men., ${ }^{416}$ Very rarely meningiomas may be in the intramedullary compartment. ${ }^{17}$ Spinal meningiomas are usually solitary, although multiplicity is observed occasionally, particularly in patients with vonReclinghausen's disease. The overall incidence of multiplicity is $1-2 \% .^{2}$

We purposefully exclude the extradural or intramedullary meningiomas from this study as they are very small in numbers and alsowe didn't get any multiplelesions in any of our patients.

Spinal meningiomas may occur simultaneously or, in association with intracranial meningiomas. ${ }^{18}$ Cushing and Eisenhardt ${ }^{19}$ found the ratio of spinal to intracranial meningiomas being 1:16, but in India the comparative incidence seems to be higher $(1: 4) .{ }^{20}$ We didn't get such cases in present study.

Plain x-rays are usually uninformative in the evaluation of patients with completely IDEM lesions, however occasionally calcification within the meningiomascan be seen in the plain x-rays. ${ }^{2,21} \mathrm{MRI}$ with or, without contrasts the imaging study of choice and is frequently sufficient for diagnosis and future surgical planning for any IDEM tumors in present days. ${ }^{22,23}$ All of our cases were evaluated with MRI. In MRI, meningiomas are usually having broad dural base, iso-intense or, slightly hypo-intense in T1-weighted image and iso-intense in T2-weighted image with homogenous contrast enhancement. The dural enhancement (dural tail) is an important finding. (Figures 1-6).

At the time of operation, every attempt was made to preserve the arachnoid to minimize the risk of spinal herniation and preferably to stay in extra-arachnoid plane during tumor resection as meningiomas are exraarachnoidal mass. Small tumors were removed in toto after separation of arachnoid and other important surrounding structures. Otherwise a piecemeal removal was preferable. In case of anterior or antero-lateral tumors, the dentate ligaments can be used as a tag for rotation of the cord to expose the tumor. For these tumors CUSA (Cavitron Ultrasonic Surgical Aspirator) is an important tool as it creates rapid debulking without displacing neural or tumor tissue. Dural attachments were coagulated in all the patients. Complete tumor removal was achieved in more than $90 \%$ of the patients (Table 7). The rate of total removal of the tumor was reported to be $82 \%$ by Levy et al. ${ }^{4} 92.6 \%$ by Roux et al. ${ }^{8}$ and $97 \%$ by Solero et al. ${ }^{1}$ Complete removal of attached dura is usually followed by no recurrence, but usually it is adequate to remove only the inner leaf of the dura in the region of meningioma insertion. ${ }^{3}$ In some cases, particularly with markedly calcified meningiomas, a small amount of tumor may be left and incomplete removal IDEM meningiomasmay also have an excellent prognosis, with no recurrence or, recurrence delayed by several years. However, epidural meningiomas or calcified meningiomas often do not have such excellent prognosis. ${ }^{4}$ Frequently, one or more nerve roots may have to be sectioned in order to remove 


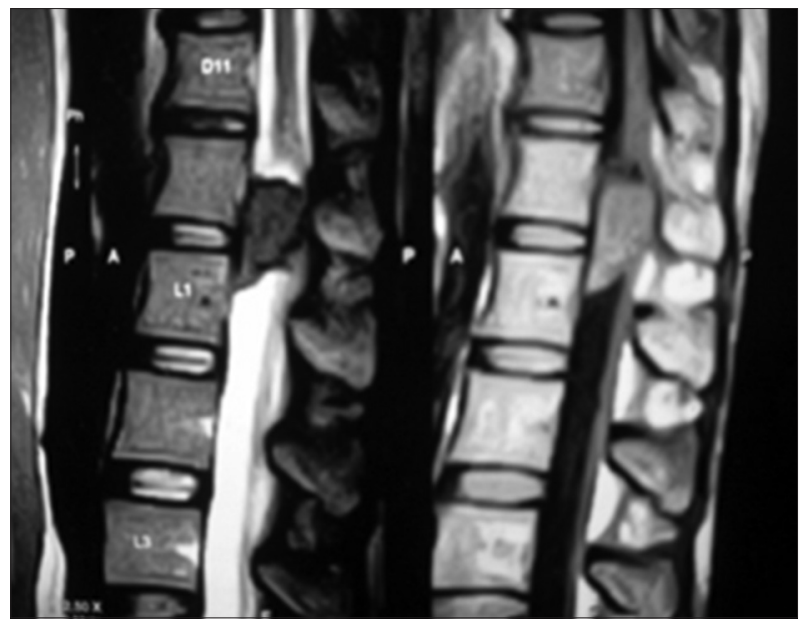

Figure 1: Dorso-lumbar meningiomas T2 \& T1

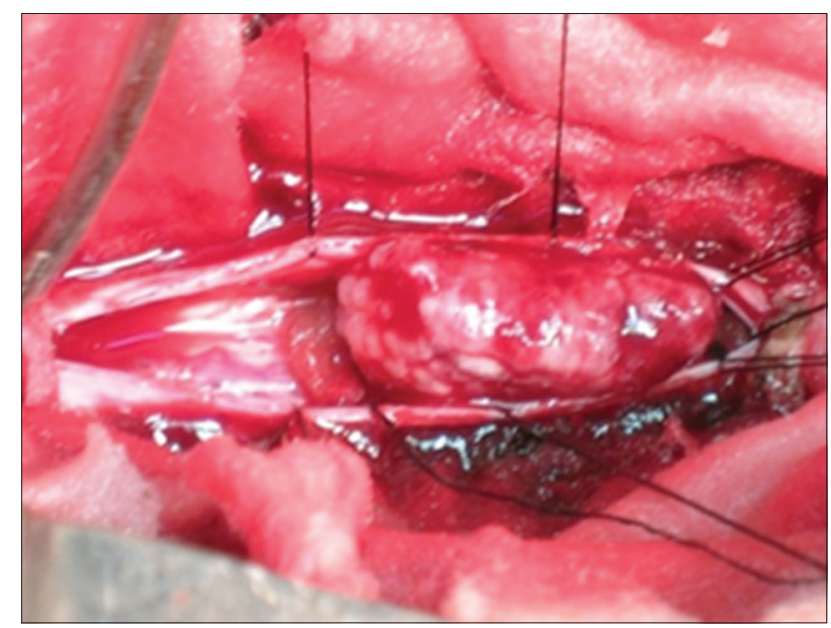

Figure 2: Per operative view IDEM meningioma

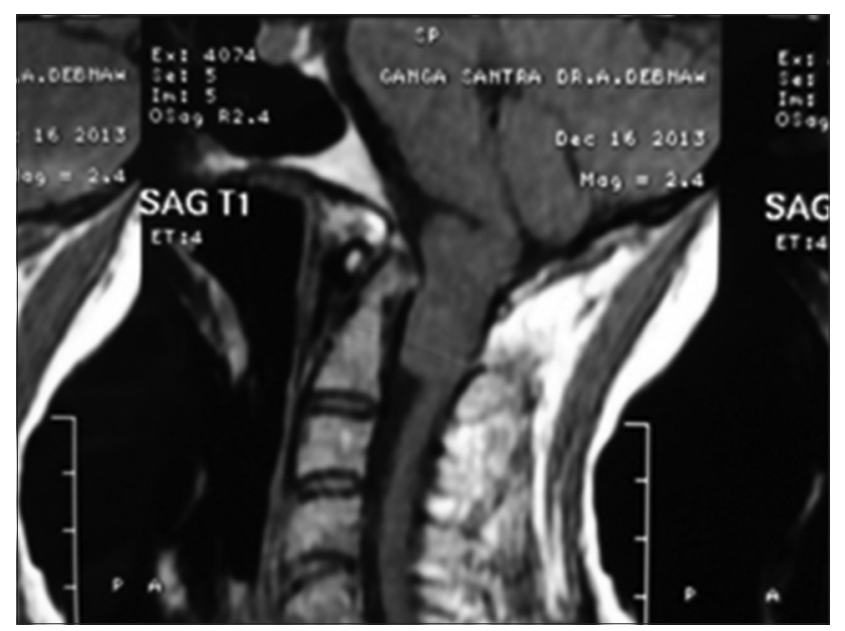

Figure 3: High cervical meningioma T1

the tumor with minimal manipulation of the spinal cord. Usually it is safe to section both anterior and posterior nerve roots from $\mathrm{C} 2$ to $\mathrm{C} 4$ as well as within the thoracic region below $\mathrm{T} 1 .{ }^{24}$ Freidberg $\mathrm{SR}^{25}$ commented in his article,

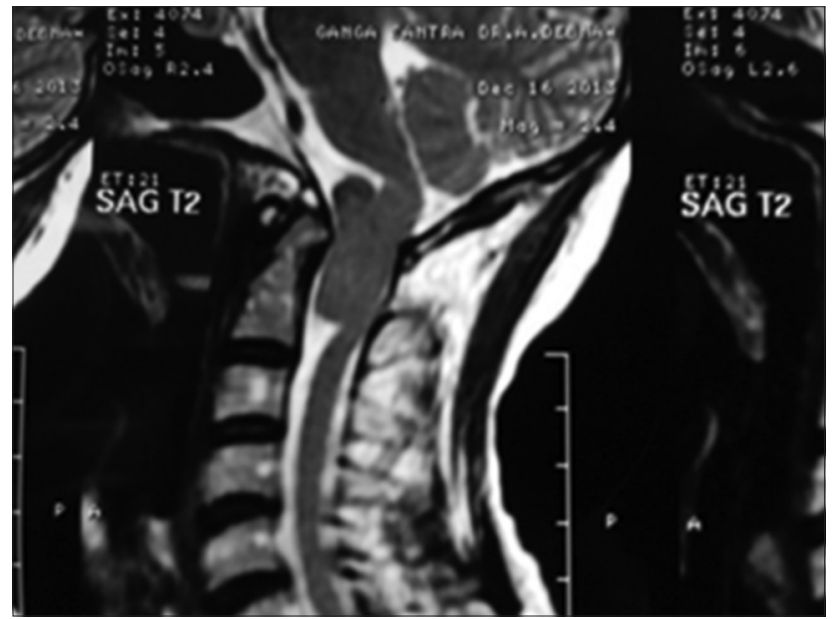

Figure 4: High cervical meningiomas T2

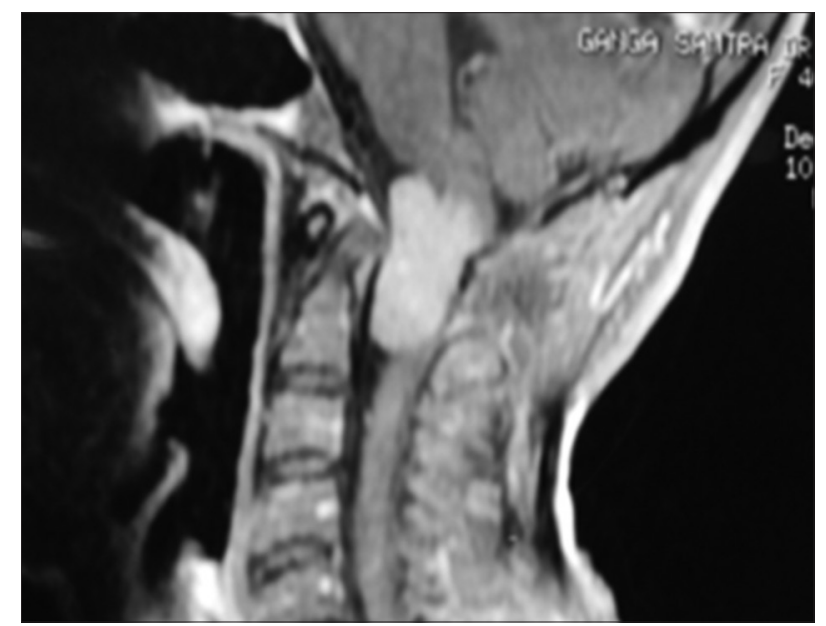

Figure 5: High cervical meningioma (contrast)

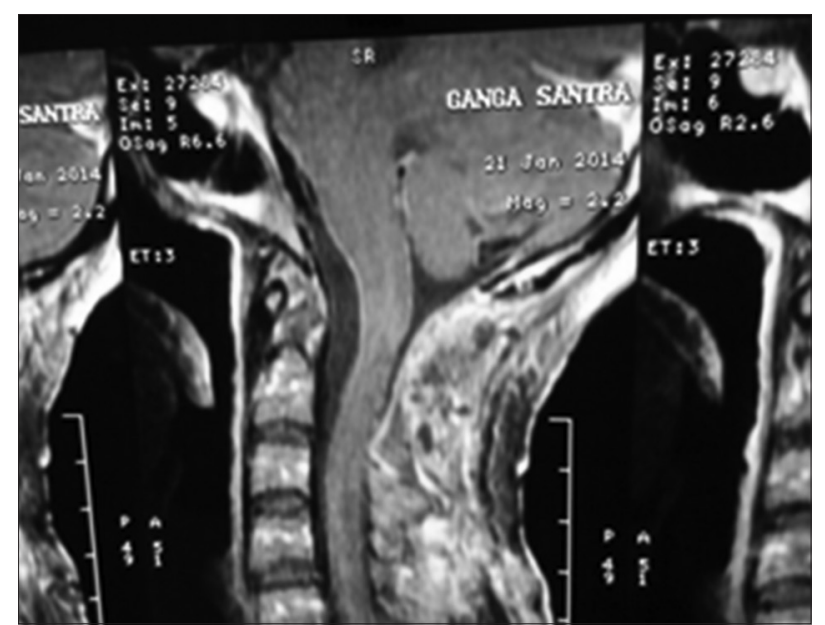

Figure 6: Post operative image of the same patient

total resection of a spinal canal meningioma usually is not difficult, but if the tumor is ventral to the cord and calcified, surgery becomes hazardous and may damage the cord'.Similar experience was noted in the present study. 


\section{Table 9: Functional outcome (According to Nurick's Grade)}

\begin{tabular}{lccc} 
Nurick's grade & No. of patient at discharge (N=75) & No. of patient at 6wks. F.U. (N=75) & No. of patient at 1yr. F.U. (N=56) \\
\hline Grade 1 & $52(69.3 \%)$ & $61(81.3 \%)$ & $45(80.3 \%)$ \\
Grade 2 & $18(24 \%)$ & $12(16 \%)$ & $08(14.28 \%)$ \\
Grade 3 & $04(05.3 \%)$ & $02(2.66 \%)$ & $02(3.57 \%)$ \\
Grade 4 & $01(1.3 \%)$ & 00 & $01(1.78 \%)$ \\
Grade 5 & 00 & 00 & 00 \\
\hline
\end{tabular}

Two (02) patients had recurrence at 1yr. follow up.

As majority of the patients present with walking difficulties, we chose the Nurick's Grading ${ }^{5}$ for clinical assessment of our patients though it was not a common scale for assessment of spinal tumors. Majority of the patient were in the grade 3 followed by grade $2 \& 4$ pre-operatively. Post operatively almost all showed remarkable improvement and more than $80 \%$ patientsbecame in grade 1 within 6 weeks of surgery (Tables 5 and 9). We didn't get any similar study to compare our result in this regard. Stein $\mathrm{BM}$ and McCormick $\mathrm{PC}^{26}$ mentioned that, the immediate results and prognosis in the common IDEM tumors including meningioma and nerve sheath tumors have been well established; when removed carefully and thoroughly, patient should be cured with excellent prognosis. Even in patients who have been devastated neurologically by the growth of these tumors before surgical intervention, there is some hope - especially in young individuals - that many of the neurosurgical abnormalities may resolve slowly in the post-operative period. It may take 18 months to 2 years to maximize the resolution of these neurological deficits and some patients have improved progressively beyond this time. Patients' age and duration of symptoms are also important prognostic factors. ${ }^{3,4}$ Once the paraplegia or quadriplegia becomes established, there is a little hope for good recovery. Spastic paraplegia has favorable prognosis. The power may not improve even after complete removal of the tumor, if paraplegia has progressed to flaccidity. ${ }^{27}$ Similar observation was also noticed in the present study.

Levy WJ Jr et al. and Solero CL et al. noted the morbidity rate is usually less than $15 \%$. Complications include CSF leak, pseudomeningocele development, wound breakdown, meningitis, arachnoiditis, syringomyelia and spinal destabilization as well as other routine complications of spinal surgery and general anaesthesia. ${ }^{1,4}$ Surgical complications occurred in the present series in $13.33 \%$ of patients, among which UTI occurred in maximum number of patients (probably due to prolong indwelling catheter) (Table 8). We didn't encounter any pseudomeningocele formation, meningitis, or syringomyelia or spinal destability in this study. Two patients had recurrence in $1 \mathrm{yr}$ follow up. In both have them tumor could not be removed in totally and one of them had partially calcified tumor, who didn't give consent for re-operation and lost from follow up after 1 year.
Solero et al. and others ${ }^{1,3,4,28}$ found no significant difference between the recurrences of spinal tumor treated with radical resection of the dura and recurrences of those treated with tumor removal and coagulation of the dural attachments. The reported recurrence rate for meningiomas that have been totally removed is $1.3 \%$ at 5 years and $6 \%$ at 14 years, and even in subtotal resection, recurrence rates of less than $15 \%$ have been noted. Excision of dural margin, in contrast to simply cauterizing the margins, is associated with a lower recurrence rate $(4-8 \%$ for dural margin cauterization and $0-5.6 \%$ for dural margin excision). ${ }^{1,4,8}$ Yoon $\mathrm{S} . \mathrm{H}^{14}$ in their 35 years study, found no recurrence of intraspinalmeningiomas once gross total resection was achieved, regardless of the control of the dural origin. Two patients $(2.6 \%)$ in our series showed recurrence in 1 year follow up. A meningioma with enplaque extension is difficult to remove grossly and has increased risk of post operativearachnoidal adhesions with delayed neurological deficits. ${ }^{4}$

\section{CONCLUSION}

- IDEM meningiomas in majority, affects females and occurs in the thoracic region; mostly arises lateral to the cord.

- Nurick's gradation is a good clinical assessment tool for IDEM lesions including meningiomas.

- Microscopic surgical dissection with total removal is the goal and gives the best long term result. However, unusual and difficult locations present a challenge to the neurosurgeons unsurpassed by any other benign lesion.

- There is no significant increased recurrence rate for simply cauterization of dural attachments instead of dural excision.

\section{REFERENCES}

1. Solero CL, Fornari M, Giombini S, Lasio G, Oliveri G, Cimino C, Pluchino $\mathrm{F}$ et al. Spinal meningiomas: review of 174 operated cases. Neurosurgery 1989; 125: 153-160.

2. Okazaki H. Fundamentals of neuropathology, $1^{\text {st }}$ Edn, Tokyo: Igaku - Shoin, 1983.

3. McCormick PC, Post KD and Stein BM. Intraduralextramedullary tumors in adults, Neurosurgery Clin North Am 1990; 1: 591-608.

4. Levy WJ, Bay J and Dohn D. Spinal cord meningiomas. 
J Neurosurg 1982; 57: 804-812.

5. Nurick S. The pathogenesis of the spinal cord disorder associated with cervical spondylosis. Brain 1972; 95:87-100.

6. Nittner K. Spinal meningiomas, nurinomas and neurofibromas hourglass tumors. In: Vinken P.J. Brayagw. (Eds.) Handbook of clinical neurology vol.20. New York: Elsevier, 1976: pp 177-322.

7. Grunberg S, Weiss MH, Spitz IM, Ahmadi J, Sadun A, Russell CA, et al. Treatment of unresectable meningiomas with the antiprogesterone mefepristone. J Neurol Neurosurg 1991; 74:861-866.

8. Roux FX, Nataf F, Pinaudeau M, Borne G, Devaux B and MederJF. Intraspinalmeningiomas: review of 54 cases with discussion of poor prognosis factors and modern therapeutic management. Surg Neurol 1996; 46: 458-463.

9. Rothman R and Simeone F. The Spine, in Weinstein J, McLain R (Eds): Tumors of the Spine, $3^{\text {rd }}$ eds. Philadelphia: WB Saunders Co.: 1992, pp 1299-1300

10. Russel $D$ and Rubinstein L. Pathology of tumors of the nervous system, in Bigner D, McLendon R, Bruner j (Eds.). London: Arnold; 1998, pp 67-111.

11. Bickerstaff ER, Small JM and Guest IA. The relapsing course of certain meningiomas in relation to pregnancy and menstruation. J Neurosurg Psychiat 1958; 21:89-91.

12. MichelsenJJ and New PFJ. Brain tumor and pregnancy. J Neurol Neurosurg Psychiat 1969; 32:305-307.

13. Schoenberg BS, Christine BW and Whisnant JP. Nervous system neoplasms and primary malignancies of other sites. The unique association between meningiomas and breast cancer. Neurology 1975; 25:705-712.

14. Yoon SH, Chung CK and Jahng TA. Surgical outcome of spinal canal meningiomas. J Korean Neurosurg Soc 2007; 42: 300-304.

15. Namer IJ, Pamir MN, Benli K, Saglam S and Erbengi A. Spinal meningiomas. Neurochirurgia (Suttg) 1987; 30: 11-15.

16. Cologero JA and Moosy J. Extradural spinal meningiomas. J Neurosurg 1972; 37: 442-477.
17. Banerjee SN, Bhowmik NN and Roy RN. Intramedullary spinal meningioma - report of a case with review of literature, Neurology (India) 1987; 35: 117-120.

18. Roda JM and Barcosne JA. Simultaneous multiple intracranial and spinal meningiomas. Neurochirugie 1992; 35:92.

19. Cushing $\mathrm{H}$ and Eisenhardt L. Meningiomas: their classification, regional behavior, life history and surgical end results. Spring field, IL: Charles C Thomas, 1938.

20. Ramamurthi B. Intraspinal compression. In: 20 years publication by the Institute of Neurology, Madras, 1970; p.78.

21. Nagi B, Kak VK and Singh I. Roentgen spectrum of spinal compression. Neurol (India) 1975; 23:40.

22. Sze G. Magnetic resonance imaging in the evaluationof spinal tumors. Cancer 1991; 67: 1229-1241.

23. Sze G, Abramson A, Krol G, Liu D, Amster J, Zimmerman RD and Deck MD. Gadolinium - DTPA in the evaluation of intraduralextramedullary spinal disease. AJNR (Am J Neuroradiol) 1988; 9:153-163.

24. Kim P, Ebersold MJ, Onofrio BM and Quast LM. Surgery of spinal nerve schwannoma. Risk of neurological deficit after resection of involved root. J Neurosurg 1989; 71:810-814.

25. Freidberg SR. Removal of an ossified ventral thoracic meningioma- Case report. J Neurosurgery 1972; 37: 728-730.

26. Stein BM and McCormick PC. Spinal intradural tumors. In: Rengachary SS, Wilkins RH (Editors) Neurosurgery Vol.2, $2^{\text {nd }}$ Ed. New York, McGraw-Hill (1996); 175: 1769-1780.

27. Ramamurthi B and Balaparameswara Rao S: Tumours of spinal cord and cauda equine, In: Ramamurthi B, Tandon P., Ramamurthi R, Sridhar K(Eds.) Text book of Neurosurgery vol.II, New Delhi, BI Churchill Livingstone Pvt. Ltd. 1996; pp 707-742.

28. Brotchi Jacques. Spinal intraduralextramedullary tumors. In: Rengachary S.S. Ellenbogen R.G (Eds). Principles of Neurosurgery, $2^{\text {nd }}$ Edn, London, Elsevier Mosby (2005): $681-688$.

\section{Authors Contribution:}

KR- Concept and design of the study, manuscript preparation, statistically analyzed and interpreted, critical revision of the manuscript; PG- Concept and design of the study, critical revision of manuscript and review of the study; SKS- Concept and design of the study, critical revision of manuscript and review of the study; PT- Concept and design of the study, critical revision of manuscript and review of the study.

\section{Work attributed to:}

Department of Neurosurgery, Nil RatanSircar Medical College, Kolkata

\section{Orcid ID:}

Dr. Kaushik Roy - iD https://orcid.org/0000-0001-8317-9840

Dr. Partha Ghosh - https://orcid.org/0000-0002-8510-7776

Prof Suniti Kumar Saha - (iD https://orcid org/0000-0002-6217-9355

Prof Parimal Tripathy - ib https://orcid.org/0000-0002-9904-8367

Source of Support: None, Conflict of Interest: None declared. 